\title{
Pinol Jean-Luc, Convois. La déportation des Juifs de France
}

Danielle Delmaire

\section{OpenEdition}

1 Journals

Édition électronique

URL : https://journals.openedition.org/tsafon/3037

DOI : $10.4000 /$ tsafon.3037

ISSN : 2609-6420

Éditeur

Association Jean-Marie Delmaire

Édition imprimée

Date de publication : 1 juillet 2020

Pagination : 187-188

ISSN : 1149-6630

\section{Référence électronique}

Danielle Delmaire, «Pinol Jean-Luc, Convois. La déportation des Juifs de France », Tsafon [En ligne]

79 | 2020, mis en ligne le 01 juillet 2020, consulté le 30 juin 2021. URL : http://

journals.openedition.org/tsafon/3037 ; DOI : https://doi.org/10.4000/tsafon.3037

Ce document a été généré automatiquement le 30 juin 2021.

Tsafon. Revues d'études juives du Nord 


\title{
Pinol Jean-Luc, Convois. La déportation des Juifs de France
}

\author{
Danielle Delmaire
}

\section{RÉFÉRENCE}

Paris, éd. du Détour, 319 p., 24,90€.

1 «Quand la cartographie aide à mieux comprendre l'histoire », tel pourrait être le soustitre de cet ouvrage qui rassemble pas moins de 130 cartes sur la déportation des Juifs de France. Il ne s'agit plus de lire des récits de témoins ou des analyses d'historiens mais de visualiser l'ampleur de la déportation, à l'échelle nationale et à l'échelle régionale, voire à l'échelle de la capitale : Paris.

Grâce aux cartes, élaborées à partir du Mémorial de la Déportation des Juifs de France de Serge Klarsfeld, accessible depuis 2012 en version numérique, les différentes manifestations de la persécution sont mises en évidence. Par exemple, les circonstances de l'arrestation varient selon le lieu d'habitation. Les cartes de Paris montrent que l'on n'est pas arrêté dans les mêmes circonstances si l'on réside dans les quartiers huppés de l'ouest parisien, là où vivent les juifs français depuis longtemps, ou dans les quartiers plus pauvres, là où se sont installés les familles juives immigrées récemment. Et pour ces familles juives immigrées, les arrestations ne sont pas exécutées dans les mêmes occasions selon que l'arrivée en France est très récente ou un peu plus ancienne. Dans tous les cas, les réseaux d'aide éventuelle ne sont pas identiques et la cartographie localise ces différences. De même, les cartes donnent une image plus globale des divers moyens d'arrestation selon qu'elle a lieu au domicile habituel ou à partir d'un refuge, ville, village ou institution. Ainsi surgit la complexité des « destins individuels » tout comme la complexité des « destins, familiaux ou collectifs ».

3 Apparaît aussi nettement la géographie de la déportation des juifs grâce aux cartes 1.1 et 1.2 : les arrestations pour la déportation ont été réalisées dans un dixième des 36000 communes que compte la France. Toutes les régions sont touchées mais il en est où les 
arrestations furent quasiment absentes : la Corse, la Bretagne et l'Alsace. Pour la région Nord-Pas-de-Calais, l'histoire se lit sur ces deux cartes où l'on distingue clairement la région lilloise, le bassin minier, depuis Lens jusqu'à Valenciennes, et le Cambrésis : c'est là où la rafle du 11 septembre 1942 fit le plus de ravages.

4 La visualisation de la déportation des juifs de France se fait aussi par graphiques, tel le graphique 2.1 qui donne les lieux de naissance des déportés selon chacun des 77 convois. Tous les lieux de naissance n'ont pas pu être listés, l'auteur se limite, fort justement, à quelques grandes villes : Paris, Strasbourg, Marseille et Oran pour la France et ses colonies, Francfort, Berlin et Vienne pour l'Europe d'expression allemande, Salonique et Constantinople pour la Méditerranée orientale, Anvers et Amsterdam pour l'Europe du Nord-Ouest et enfin Varsovie pour l'aire polonaise. Pour Paris, les petites colonnes du graphique sont plus hautes pour les convois d'août 1942, mettant en évidence la densité des départs dus à la rafle du Vel' d'Hiv. La rafle de Marseille des 22-24 janvier 1943 se lit avec l'allongement des colonnes de Marseille et d'Oran pour le convoi 52 du 23 mars 1943. La présence majoritaire des juifs nés à Varsovie dans les convois 1 à 16 (jusqu'au 7 août 1942) montre qu'ils furent bien les premières victimes de la déportation qui visait, dans un premier temps et prioritairement, les étrangers. Ce graphique est particulièrement éloquent, il est difficile d'en faire une analyse complète dans une brève recension.

Avec ce graphique, toujours, apparaît le calendrier de la déportation et ses différentes phases. Celles-ci sont présentées dans le chapitre trois, chacune groupant un peu moins ou un peu plus d'une dizaine de convois. Et bien sûr des cartes illustrent ces phases si bien que la géographie rejoint la chronologie. Ce chapitre intègre le convoi parti de Malines après la rafle du 11 septembre 1942 dans le Nord-Pas-de-Calais et l'auteur en souligne la particularité en évoquant un convoi « atypique par rapport à l'ensemble des convois partis de Drancy » (p. 72).

6 En réalité l'ouvrage outrepasse l'annonce du titre puisque le chapitre cinq donne la cartographie des "fusillés, guillotinés, massacrés », non déportés, avec les cartes des régions particulièrement touchées par les massacres, comme la Dordogne ou la région lyonnaise.

7 Une carte des Justes complète cet ensemble. L'auteur a soin de préciser qu'une telle carte ne peut rendre compte que partiellement des sauvetages dans la mesure où les dossiers de Yad Vashem sont constitués à partir des témoignages des sauvés. Si la personne secourue ne fait aucune démarche, son ou ses sauveteurs ne seront jamais honorés du titre de Justes parmi les Nations et le sauvetage reste inconnu.

8 Enfin dans les 80 pages d'annexes, se suivent les cartes de chacun des convois donnant les effectifs, la localisation des arrestations ou des rafles.

Quel ouvrage est parfait? Il faut donc émettre quelques reproches. Celui d'abord de confondre «zone rattachée » et « zone annexée » : la Moselle et les deux départements alsaciens ne sont pas « rattachés au Reich» (p. 21 et cartes p. 22-23) mais annexés, tandis que le Nord et le Pas-de-Calais sont rattachés au commandement militaire de Bruxelles. Il y a là une différence administrative importante pour le sort des populations en général et des juifs en particulier. Quant à la carte 1.8, p. 33, elle donne à voir les lieux où les juifs sont décédés dans des camps d'internement et dans des lieux de transit français. Aucune trace des camps du Boulonnais où pourtant quelques juifs sont décédés. Mais il est vrai que ces juifs étaient originaires de Belgique et non de 
France. Camps en France pour juifs de Belgique : à quelle histoire appartiennent-ils ? De France ou de Belgique? (Lire l'introduction au dossier).

10 Malgré ces rares écarts, il convient de conclure avec Serge Klarsfeld qui a préfacé l'ouvrage : «ce présent livre est un nouveau développement dans l'historiographie de la Shoah » (p. 5). Et ajoutons que J-L Pinol, professeur émérite de l'ENS de Lyon, a fourni un excellent outil pédagogique pour ses collègues de l'enseignement secondaire qui souhaitent focaliser leur cours sur l'histoire régionale, celle de leurs élèves, grâce à ces nombreuses cartes. 